\title{
USO DE OFICINAS COMO PRÁTICA PEDAGÓGICA PARA A ASSIMILAÇÃO E CONSTRUÇÃO DE CONCEITOS
}

\author{
Camila Baleiro Okado Tamashiro ${ }^{1}$
}

\section{Introdução}

Cartolinas coloridas sobre a mesa. Cola, tesoura, régua e caneta para quadro branco as acompanham ao lado. Assim, iniciam-se as primeiras aulas da sexta-feira: uma oficina voltada para a assimilação dos conceitos aprendidos no componente curricular de Linguagem de Programação Orientada a Objetos (LPOO), na segunda série do ensino técnico em informática integrado ao médio (ETIM).

Ao entrarem, os alunos deparam-se com as mesas organizadas em módulos, compostos de quatro carteiras e cadeiras cada. Tamanha é a estranheza ilustrada no olhar de cada estudante que ali chega. Aos poucos vão se agrupando, e curiosos sussurram sua curiosidade com comentários sobre como fazer uma aula de informática com o uso desses materiais sobre a mesa.
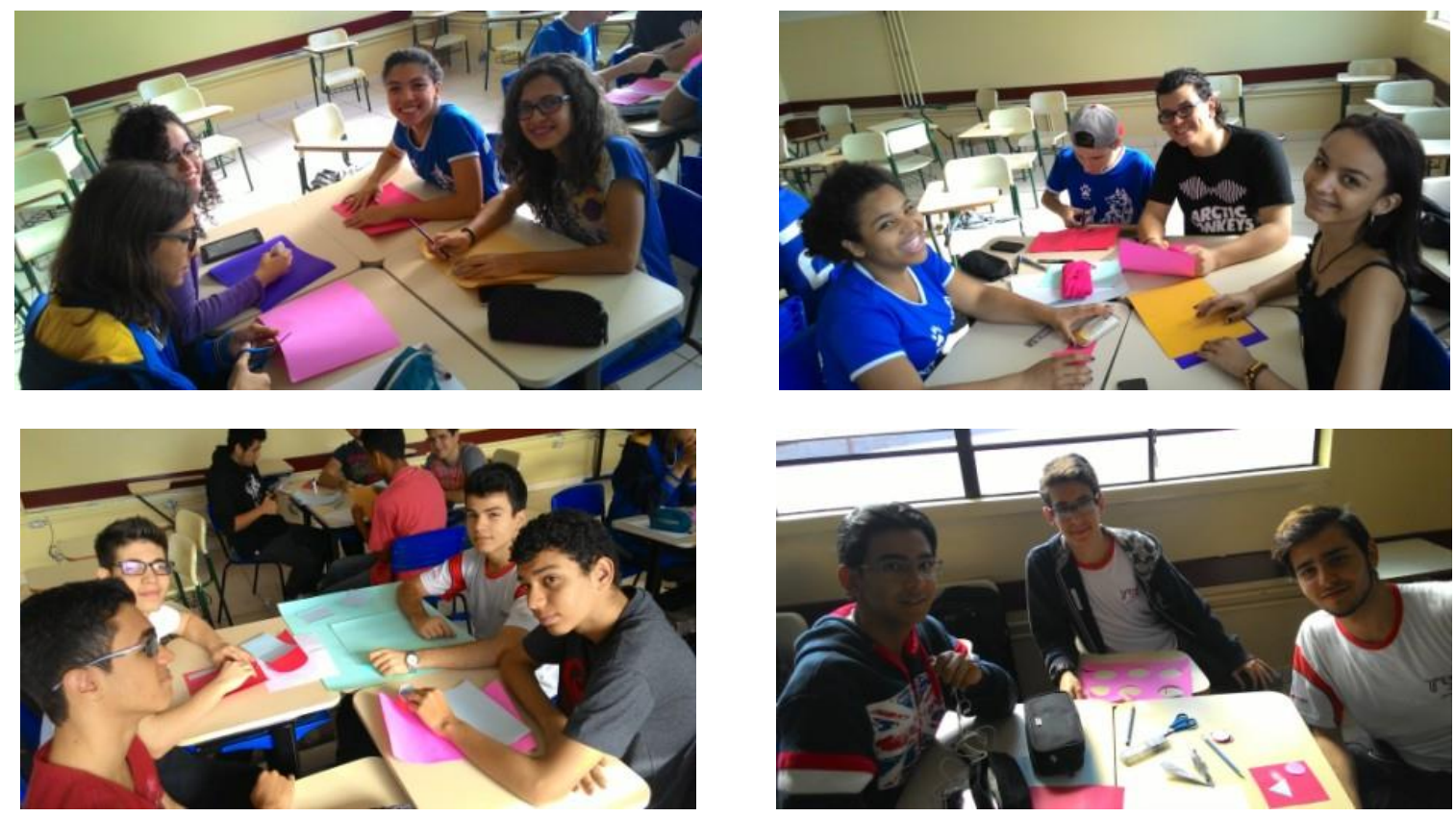

FIGURA 1: Confecção das formas geométricas na cartolina

Após organizarem-se, inicia-se a primeira etapa da oficina: a confecção de triângulos, círculos e quadrados com as cartolinas coloridas - tal processo de construção ocorre de forma harmoniosa, despertando a curiosidade dos alunos quanto ao próximo passo e o que será construído ao final.

\section{Desenvolvimento}

Passo a passo, as cartolinas tomam formas; os diagramas são formados. Cada etapa da oficina e construção do diagrama, alinha-se ao contexto teórico e prático ministrado em aulas anteriores.

\footnotetext{
${ }^{1}$ E-mail: camila.okado@etec.sp.gov.br.
} 

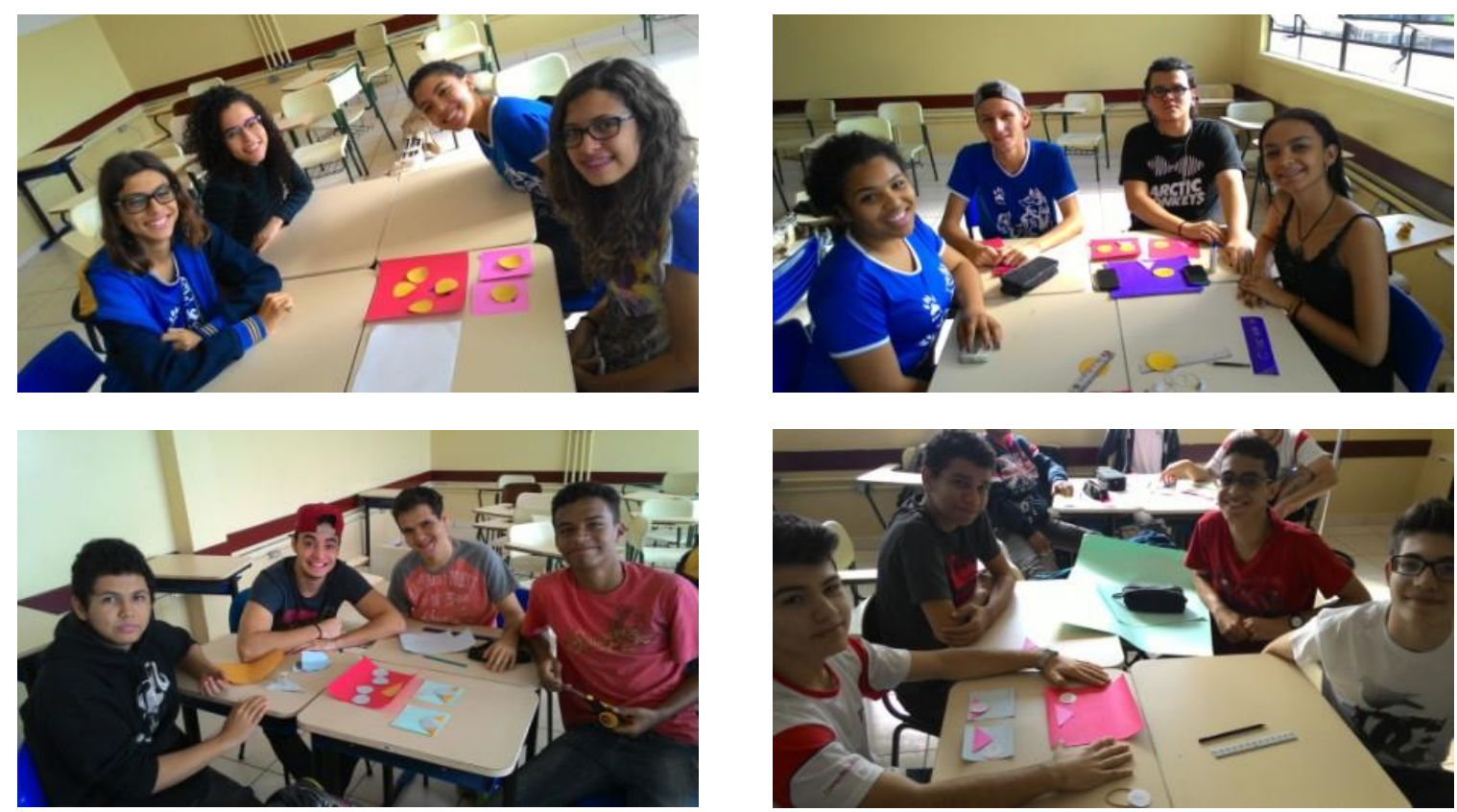

FIGURA 2: Confecção das formas geométricas na cartolina

Ao se utilizar a oficina, a estrutura do procedimento didático torna-se sinestésica, de forma a unir a comunicação verbal à visual. Além de despertar a curiosidade nos alunos sobre como a montagem e organização das formas confeccionadas contribuirá para a elaboração dos diagramas, a atividade evidencia como estes compreendem o comportamento da linguagem de programação, mas por meio de um olhar mais simbólico, colorido e interativo.

Ao se incorporarem à aula elementos artísticos e plásticos, a professora sensibilizou seus alunos, tirando-os de sua zona de conforto, pois foi necessário um processo de preparação dos elementos para seu uso em sala de aula, o que estabeleceu, nesse momento, a interação entre duas ou mais disciplinas e a relação de interatividade. Isso possibilitou o diálogo entre os interessados, como mencionou Carmo (2004) em seu artigo "A interdisciplinaridade e o trabalho com projetos".

Confeccionadas as figuras geométricas, inicia-se o procedimento didático de desconstrução da disciplina, ou seja, o componente que busca desenvolver a compreensão e as técnicas de programação utilizadas nas linguagens de programação orientadas a objetos. Dessa forma, os conceitos dos objetos computacionais já estabelecidos e compreendidos pelos alunos são relacionados às figuras confeccionadas na oficina, sendo o formato de cada uma delas um simbolização da padronização universal de modelagem de objetos (a UML): 


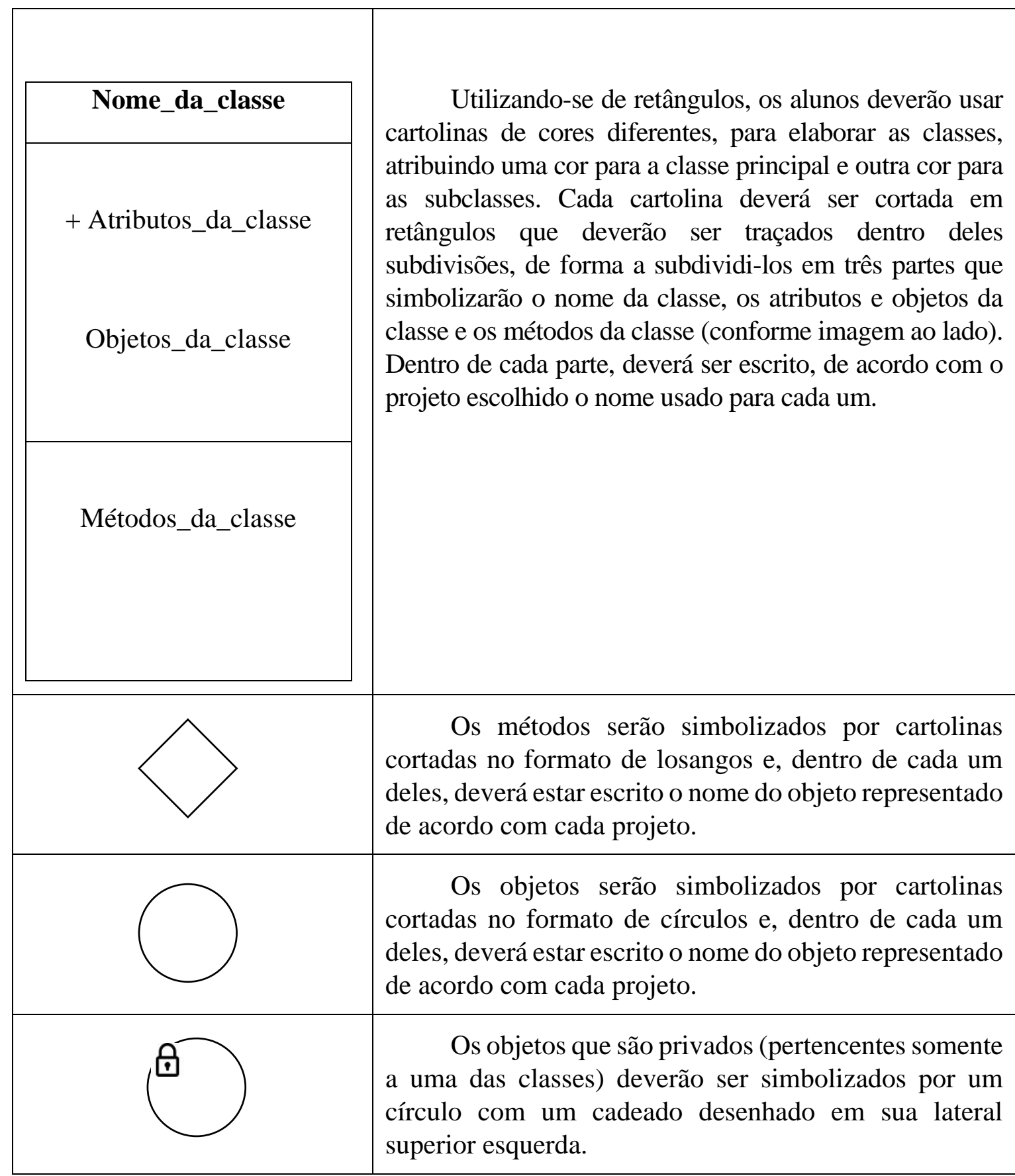

TABELA 1: Tabela de representação dos objetos computacionais

Ao compreender o contexto e a função de cada objeto computacional, por meio de interação e interlocução, cada equipe - composta por quatro alunos - deverá identificar, dentro de um projeto computacional já existente, cada um dos objetos ali envolvidos, de forma que, para cada classe, método e objetos criados, deverá haver a mesma quantidade de retângulos, quadrados e círculos.

Isso porque, durante o processo de identificação dos objetos computacionais, os alunos precisam desenvolver habilidades para estabelecer as ligações necessárias entre cada um dos elementos, de modo a compreender as relações existentes entre os objetos, métodos e classes dentro de um projeto. 
Inseridos nesse processo de produção artístico e plástico, os alunos buscaram fazer as ligações usando outros elementos, como marcador de quadro branco, marcador de texto, fita adesiva colorida, papel espelho, corretivo em caneta, dentre outros materiais.
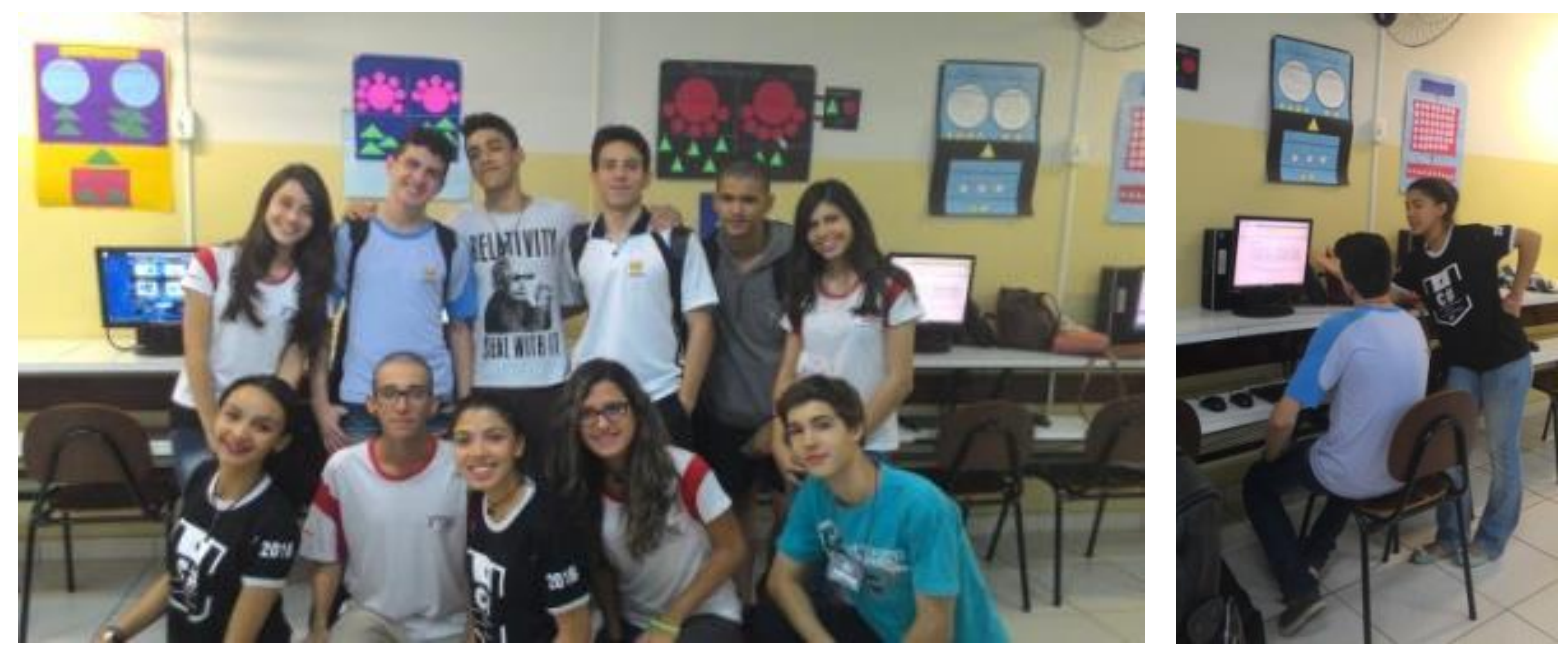

FIGURA 3: Estudantes expondo e explanando seus trabalhos aos visitantes

Ao término da elaboração de seus trabalhos, os alunos expuseram seus projetos finalizados, fixando suas cartolinas acima dos computadores do laboratório de informática, de modo que, no computador, apresentava-se o projeto computacional desenvolvido e, acima dele, a cartolina com os objetos computacionais nele existentes.

\section{Conclusões}

Ao se inserir a estratégia de ensino de oficina e incentivar sua produção dentro de um procedimento didático, observa-se inicialmente a curiosidade do aluno, despertando neste o interesse em participar mais ativamente do aprendizado e, com isso, quebrar paradigmas quanto à forma de se ministrar aulas em componentes do curso de informática.

Por se tratar de uma sala ETIM em informática que cursa a segunda série, foram verificadas grande receptividade e nostalgia dos alunos quanto ao ato de voltarem a ter contato com materiais artísticos e plásticos.

Durante a construção do objeto, observou-se que o aluno, ao trabalhar em equipe, passa por processos de aprendizagem em relação à comunicação, promovendo um tipo de interação em que a linguagem antecipa o conhecimento e a compreensão do conceito, já evidenciada por Pereira (2015), em seu artigo "Piaget, Vygotsky e Wallon: Contribuições para os estudos da linguagem".

Ao finalizar a oficina, verificou-se a satisfação de cada equipe com o resultado como também a satisfação pessoal de cada aluno por enfim compreender a relação entre os objetos computacionais (tanto no âmbito da linguagem de programação, quanto no que tange a confecção da oficina).

Ao mostrarem aos demais alunos da escola o seu trabalho, os alunos vivenciaram um momento de satisfação pessoal, por terem conseguido desenvolver a oficina e também por conseguirem entender e explicar conceitos tão complexos.

Após a exibição dos projetos, foi realizada uma pesquisa qualitativa com os alunos participantes da oficina, em que foram compartilhados as experiências e os aprendizados dos envolvidos. Observou-se que a maioria dos alunos participantes da oficina compreendeu os 
conceitos e conseguiu os abstrai, de forma a imaginar a relação dos objetos e métodos com suas respectivas classes computacionais.

Com isso, a oficina atingiu o seu objetivo: desenvolver técnicas para os alunos compreenderem a relação dos objetos computacionais envolvidos em uma linguagem de programação orientada a objetos.

A partir do relato, verificou-se que a técnica adotada também ampliou a forma de aprendizagem na área de informática, a partir da adoção de um procedimento didático que visou unir áreas distintas - informática e artes -, beneficiando todos os envolvidos.

\section{Referências}

ASSOCIAÇÃO BRASILEIRA DE NORMAS TÉCNICAS. NBR 10520: informação e documentação: citações em documentos: apresentação. Rio de Janeiro, 2002.

ASSOCIAÇÃO BRASILEIRA DE NORMAS TÉCNICAS. NBR 14724: informação e documentação: trabalhos acadêmicos - apresentação. Rio de Janeiro, 2005.

ASSOCIAÇÃO BRASILEIRA DE NORMAS TÉCNICAS. NBR 6023: informação e documentação - referências - elaboração. Rio de Janeiro, 2002.

BRASIL. Lei das diretrizes e bases da educação nacional (LEI No 9.394, de 20 de dezembro de 1996). Disponível em: 〈http://www.planalto.gov.br/ccivil_03/Leis/L9394.htm>. Acesso em: 01 out. 2016.

CARMO, J. G. B. A interdisciplinaridade e o trabalho com projetos. Disponível em: <http://www.educacaoliteratura.com/index\%20122.htm>. Acesso em: 01 out. 2015.

CETECPS. Formação pedagógica para docentes da educação profissional. Centro Paula Souza: São Paulo, 2007.

DIVERSOS, Manual para a elaboração do Trabalho de Conclusão de Curso das Escolas Técnicas do Centro Paula Souza, 2015.

PEREIRA, C. L. Piaget, Vygotsky e Wallon: contribuições para os estudos da linguagem. Psicologia em Estudo, v. 17, n. 2. Disponível em: <http://www.scielo.br/scielo.php?script=sci_arttext\&pid=S1413-73722012000200011>.

Acesso em: 05 ago. 2017. 